aystagmus. The vision was greatly impaired-with both eyes together for distance about $\frac{6}{8}$, with movements of the head and effort. She had been under observation all her life at long intervals and was first seen when 10 months old. No accident or disease preceded the condition described. The mother stated that her father and her husband's father were first cousins, and their respective mothers were sisters. She told me that she was not sure of the relationship on her husband's side in the previous generation, but that of her four grandparents on her own side three bore the same name as herself originally.

Case 3-A specimen was exhibited of a right eyeball lately excised from a lad, aged seven and a half years. The patient was a large boy with a big appetite. The disease had existed from birth and had been under observation ever since. The comea was large and fairly translucent and the coats were thinned, and the eye gradually increased in size until discomfort and photophobia necessitated excision of the globe. The vision was entirely lost and the nerve could be seen to be atrophied before operation. The cornea was about 15 millimetres across-according to Priestley Smith the normal cornea should measure from 11 to 12 millimetres. It was only just possible to deliver the eyeball during the remaval without cutting the outer canthus; it measured 30 millimetres and 33 millimetres in long and short diameter. The other eye (the left) had less than normal vision ( $\frac{6}{18}$ partly). The cornea measured the extraordinary diameter of 14 millimetres and the eyeball appeared large, but there was no lack of lustre in the cornea and it only suggested an unusually fine eye. The pupil acted well to light and there was no tension. There was nothing remarkable in the family history.

Buphthalmos, as in these cases, is a congenital disease, but it is quite possible to have a similar disorder in young subjects as a consequence of disease or injury. Treacher Collins has made observations which fully confirm the opinion of clinical observers who consider the disease to be glaucoma but occurring in young subjects. The coats of the eye yielded ander the intraocular pressure. The iris structures in the prenatal state failed to be separated from the cornea at the filtration angle, and the microscope revealed that this was not inflammatory in the first instance but a congenital failure. ${ }^{2}$

In treatment operative proceedings, sclerotomy or iridectomy, have not proved satisfactory; it would be best in most cases to use eserine, and in any case to avoid atropine. The patient in Case 1 is improving under eserine. In diagnosis the large surface area of the cornea with no injury or disease to cause stretching, softening, or opacity, is the most important to notice. Here the keratometer of Priestley Smith is of great use in making the first observation and record. The unusual size of the left cornea in the lad who lost the right eye from this disease (Case 3 ) must be evidence that the mischief was symmetrical.

The cornea is the most precocious of all the structures of the body. The eye generally may be said to take a precedence, and the cornea is the earliest part of the eye to attain perfection. It is a most interesting fact that the cornea attains its full size at five years of age (Priestley Smith). The cornex are formed thus early and we look through the same sized windows at five years of age as we do when we attain to the age of 40 years. Very different is this from the growth of the orystalline lens which grows slowly and steadily through early life to old age and this fact has bearings on glaucoma of the middle-aged or senile eye. This precocity of the corneal growth has a most interesting effect on opacities and scars. Compare, for instance, the scar on the skin of an infant-a familiar instance is a vaccination scar which grows until the infantile mark has become in the adult arm a cicatrix of great size and usually is far larger than any subsequent cicatrices from vaccinations of later life. It has been well remarked by Sir James Paget that a scar the size of the little finger of the infant might grow to the size of the little finger of the adult. But in the face, which does not grow proportionally with the limbs, the growth in the scar is not so evident. On the cornea, as a non vascular structure, the cicatrix is likely to become relatively smaller, and in any case the opacity has little chance of growing to impair further the translucency of this most precious structure. In fact, the opacity or cicatrix on the

2 Transactions of the Ophthalmological Society of the United IKingdom, vol, xvi., p. 348 . cornea does not grow at any time of life; on the contrary, it tends to lessen in size and becomes less opaque. The scar of a perforation in the infantile cornea, as in pyramidal cataract, is often extraordinarily slight ard diff. cult to see in the adult, but if the iris be adherent and remain so the tissues are vascularised and the opacity is more dense.

Nebulous conditions of the infantile cornea, though they cause great anxiety, are often serious, not so much from the opacity, which may prove transient, as from the various complications which result, as squint, nystagmus, and loss of retinal function. It is a serious matter to shut off light from the retina during the first years of life and the windows thus early opened must not be opened in vain. A cloudy cornea may clear up and yet leave the vision seriously impaired. The feeble vision of a squinting eye, when the other eye does all the work, shows the importance also of the stimulus of objects ignored by the squinting eye (amblyopia from exclusion). The eye affected never learns to fix an object or to see it clearly. The eye moves with amazing rapidity under the stimulus of a flying object. Even nystagmus may be observed under certain conditions of experiment, as when flying objects are watched from the window of a travelling railway-carriage movements of the eye are produced which without such stimulus would be impossible.

The foregoing considerations are put forward to show that, even if the buphtbalmos be stationary as to the essential glaucomatous symptoms, from the point of view of an opaque or stretched cornea the disease is very grave and threatening. The congenital condition described by Treacher Collins led to the progressive stretching of the eyeball from intraocular pressure and in Case 3 to the loss of the eye. Richardson Cross ${ }^{3}$ has related cases both of congenital buphthalmos and of buphthalmos when secondary to injury or disease. The latter would be recognised by the same signs. It is well to notice that opacities of the cornea the result of hereditary syphilis are of the nature of interstitial deposits like gummata and rarely appear in early infancy, but usually at the age of from six to 15 years-i.e., not until the cornea has attained its full size. Here also considerable vascularity of the correa is commonly associated. It is not difficult thus to exclude congenital syphilis from the diagnosis.

The three cases above mentioned at three stages of growth from infancy to adult age illustrate very well the course of buphthalmos in its clinical aspect.

Cambridge.

\section{A NOTE ON SYPHILIS IN RELATION TO LIFE ASSURANCE, WITH AN EXAMI- NATION OF 500 CONSECUTIVE CLAIMS.}

BY F. PARKES WEBER, M.D. CANTAB., F.R C.P. LOND, PHYSICIAN TO THE GERMAN HOSPITAL, DALSTON; ASSISTAN'I PHYBICIAN TO THE MOUNT VERNOX FOSPI'TA FUR CONELMPTION.

Professor J. W. RUNEBERG ${ }^{3}$ of Helsingfors, in his address to the third Northern Life Assurance Congress, analysed a consecutive series of 734 deaths amongst persons assured by the Kaleva Company, extending over the period from the foundation of the company in 1875 to the year 1897 inclusive. He came to the conclusion that 15 per cent. of the deaths were more or less brought about by syphilitic infection, whilst during the same period 21.3 per cent. could be assigned to tuberculous affections and 10 per cent. to pneumonia. Thus syphilis, according to Runeberg's estimation, ranked next to tuberculosis in frequency amongst the causes of death. Moreover, Björksten, the medical director of the company, found that of persons insured during the 20 years up to $189512 \cdot 6$ per cent. of those who gave a history of syphilis died, whilst the mortality was only $6 \cdot 1$ per cent. amongst those who denied infection. Out of the 734 deaths Runeberg first selected 84 which he considered might be regarded as to some extent the result of previous syphilitic infection, most of them as 
syphilitic or post.syphilitic affections of the heart and central nervou; system. In not all of these cases, however, was there undoubted evidence of primary or secondary syphilis. Thus, of the 22 cases of general paralysis in 11 cases a history of syphilis was given at the time of assurance and in five others medical evidence of syphilis was obtained, but in three there was a history of "soft chancre" only, and in the remaining three no evidence of infection was forthcoming. In the following cases also a history of "soft chancre" only could be obtained : a death from tabes dorsalis and cardiac valvular disease at the age of 30 years; a death from aortic aneurysm at the age of 37 years; fatal apoplexy at the age of 40 years; and deaths from "heart-stroke" ("Herzschlag," syncope) at the ages of 35 and 50 years. These 84 cases, however, constituted only 11.4 per cent. of the total number of deaths from all causes. Runeberg tabulated 47 other cases in which there was no history of syphilis but in which death occurred under the age of 50 years from "heart-stroke," cerebral hæmorrhage, or cerebral softening. He argued that about 75 per cent. of these cerebral cases and about 50 per cent. of the "heart-stroke" cases were probably in reality due to syphilitic disease of blood-vessels, and in this way he brought the number of deaths more or less caused by syphilitic infection up to 15 per cent. of the total.

Various objections may be raised against Runeberg's figures. In the first place, in the cases in which a history of syphilis, or at least doubtful syphilis, was obtained and in which Runeberg considered the death to be more or less the result of the specific disease it may be questioned whether the actual cause of death (" heart-stroke," cerebral hæmorrhage, \&c.) was not in some of them altogether independent of the syphilis. Furthermore, in regard to the cases without any history of syphilis but in which death occurred under the age of 50 years from "heart-stroke," cerebral hæmorrhage, or cerebral softening (thrombosis), was Runeberg justified in considering so high a proportion (75 per cent. of the cerebral cases and 50 per cent. of the cardiac cases) as probably due to syphilitic vascular disease? Was he justified in attributing all the deaths from general paralysis and tabes dorsalis to previous syphilitic infection? Was he right in supposing that the aortic aneurysm which caused the death at 37 years was of syphilitic origin?

Few will, I think, consider Runeberg wrong in regarding syphilis as a factor in all the cases of general paralysis and tabes. It is not necessary to go as far as some authorities do and affirm, "No syphilis, no general paralysis or tabes," in order to admit, as I believe the balance of evidence forces us to, that general paralysis and tabes seldom or hardly ever occur in persons who have never had syphilis. Overstrain, \&c., are doubtless exciting causes of aortic aneurysm, but syphilis has long been suspected to be a predisposing cause. " The disease shows a partiality for the classes of men (soldiers, \&c.) amongst whom syphilis is specially prevalent, and, moreover, the favourite age of incidence for aortic aneurysm is not the same as that for ordinary atheroma. Dr. Thomas Hayden, out of 92 cases of aortic aneurysm analysed by him, found that 60 occurred between the ages of 30 years and 50 years, whereas he found that atheroma was most common after the age of 60 years. I believe I happened to be one of the first to bring forward this relatively early age at which aneurysm occurs as an argument in favour of its inflammatory, not merely degenerative, origin. In a short paper in $1896^{3}$ I concluded "that aneurysm of the aorta is induced more often by the yielding of a portion of its wall affected by syphilitic or other inflammation than of a portion affected by simple atheroma"; and now I feel disposed to regard aneurysm (of course excluding the rare cases due to embolism and malignant endocarditis) as usually the result of a specific syphilitic disease of the arterial wall.

Without discussing each point separately I will state my belief that Professor Runeberg can hardly have much overestimated the influence played by syphilis in the series of cases which he investigated, that is to say, if one may read his conclusions as follows : that syphilis played some part in inducing 15 per cent. of the total number of deaths. It would be a very different thing to affirm that 15 per cent. of the deaths were due to syphilis, for in many cases one may suppose (by analogy with one's own and other observations) that other causes have played a part as well as

2 See Dr. F. W. Mott's account of "Svphilitic Arteritis" in Allbutt's System of Medieine, vol, vi., 1899, pp. 303 et seq.

s Syphilis and the Etiology of Atheroma, American Journal of the Medical Sciences, May, 1896. syphilis and that such other causes would sometimes by themselves have been sufficient to induce death, at period indeed, but still prematurely.

Yet,. though so far accepting Runeberg's conclusions,"I wished to get the opportunity of comparing his figures with some obtained from an English source. Such an opportunity was given me by the courtesy of Mr. H. Cockburn, the manager and actuary of the life department of the North British and Mercantile Insurance Company in London. The last 500 claims were examined-that is to say, a consecutive series of 500 in which a medical examination had been required on insurance; those in which the life had been accepted without special medical examination were altogether omitted. Most of the 500 were males, only 45 being females. The males aged 65 years or over numbered 219 and the females 21 . The males who died before the age of 65 years numbered 236 and the females 24 . In only three out of all the cases was a history of syphilis given and in none of these cases did the syphilis seem to have anything to do with the death. All the three persons were males. One died at the age of 56 years from vesical calculus, ulceration, and hæmorrhage, another died at the age of 31 years from tetanus consequent on a fracture, and the third died at 53 years of age from shock connected with an operation for appendicitis. The last was a big stout man of the kind who bear operations badly; at the age of 35 years, when his life was accepted, he was six feet two inches high and weighed 18 stones.

'The following list, however, shows, I think conclusirri, that syphilis was to some extent a cause of death in a cortain number of the cases. The list includes all the cievibs out of the total 500 which may be regarded as thrcwing light on the question.

\begin{tabular}{|c|c|c|c|}
\hline No. & Sex. & $\begin{array}{l}\text { Years } \\
\text { of age. }\end{array}$ & Cause of death. \\
\hline 1 & M. & 37 & General paralysis. \\
\hline 2 & M. & 43 & , \\
\hline 3 & M. & 46 & General paralysis; convulsions. \\
\hline 4 & M. & 46 & General paralysis; apoplexy. \\
\hline 5 & M. & 51 & General paralysis. \\
\hline 6 & M. & 52 & , \\
\hline 7 & M. & 52 & General paralysis; diarrhœa ; exhaustion. \\
\hline 8 & M. & 53 & General paralysis; exhaustion. \\
\hline 9 & M. & 68 & General paralysis. \\
\hline 10 & II. & 70 & General paralysis; exhaustion. \\
\hline 11 & M. & 47 & Locomotor ataxy; chronic cystitis. \\
\hline 12 & M. & 51 & $\begin{array}{l}\text { Tabes dorsalis (two years); ascites (four } \\
\text { months); cardiac paralysis. }\end{array}$ \\
\hline 13 & M. & 45 & $\begin{array}{l}\text { Cardiac and respiratory paralysis; locomotor } \\
\text { ataxy. }\end{array}$ \\
\hline 14 & M. & 59 & Cerebral apoplexy; t tabes dorsalis. \\
\hline 15 & M. & 58 & $\begin{array}{l}\text { Posterior and lateral sclerosis (12 years) } \\
\text { bedsores; exhaustion. }\end{array}$ \\
\hline 16 & M. & 49 & $\begin{array}{l}\text { Ataxic paraplegia (11 months); septicæmia } \\
\text { (four months); cardiac failure. }\end{array}$ \\
\hline 17 & $\mathrm{~F}$. & 39 & Acute softening of the brain. \\
\hline 18 & M. & 43 & Cerebral softening; coma. \\
\hline 19 & M. & 43 & , \\
\hline 20 & M. & 44 & Apoplexy. \\
\hline 21 & M. & 47 & Apoplexy (four hours). \\
\hline 22 & M. & 49 & Syncope due to fatty degeneration of the heart. \\
\hline 23 & M. & 49 & Acute dilatation of the heart. \\
\hline 24 & M. & 43 & Sudden death, probably from the heart. \\
\hline 25 & M. & 49 & Cardiac disease; syncope. \\
\hline 26 & M. & 43 & Aortic regurgitation; angina pectoris; syncope \\
\hline 27 & M. & 50 & Gout; angina pectoris. \\
\hline 28 & M. & 50 & Heart failure. \\
\hline 29 & M. & 46 & Thoracie aneurysm (ascending aorta). \\
\hline 30 & M. & 63 & Aneurysm of aorta (six months); asthenia. \\
\hline
\end{tabular}

I think that it is not too much to suppose that in the cases numbered 1 to 8 , all cases of general paralysis in which death occurred before the age of 55 years, syphilis had some share in the death. I would, however, omit No. 9 and No. 10, which, though certified as general paralysis, may on account of the age have really belonged to a different category. In all the cases of tabes dorsalis (No. 11 to 
No. 14) syphilis probably played a part. In the cases of other spinal affections (No. 15 and No. 16), however, there is no sufficient reason for believing that syphilis was a cause. No. 17 to No. 21 are apparently all deaths under the age of 50 years from cerebral hæmorrhage or thrombosis, and (following Runeberg) I will suppose that syphilis was a factor in 75 per cent. - that is, in at least three of these five cases. No. 22 to No. 30 are deaths from "heart-stroke" at 50 years of age or under and deaths from aortic aneurysm. In one of the two cases of aneurysm, however, the age was 63 years and in two of the seven heart cases the age of 50 years was already reached; but in order to compare results with thos of Runeberg I admit that in three cases (i.e., in half of the remaining six cases) a syphilitic infection may be presumed to have been present and to have helped to induce the early death.

According to this way of looking at the certified causes of death syphilis played a part in 18 out of 500 cases (eight cases of general paralysis, four cases of tabes dorsalis, three cases of brain disease, and three cases of cardiac or aortic disease) -that is, in 3.6 per cent. I do not think that this is too large an estimate, and it is not improbable that syphilis may have had a share in a few of the other deaths-e.g., in one or two supposed to be from cirrhosis or hypertrophic cirrbosis of the liver. $A s$ in patients known to have been infected with syphilis the ultimate death is comparatively rarely connected in any way with the syphilis, it becomes quite clear that if death can with any probability be attributed to syphilis in 18 of the cases the disease will have occurred in a vastly greater number. Iet at the medical examinations for life incurance a history of previous syphilis was forthcoming in only three of the total 500 cases. However, in some instances the disease may have been contracted after the date of assurance, and in some cases the applicant for insurance may have under-estimated the importance of the previous venereal disease or have been really ignorant that he had had any at all. Although it is probable that a history of syphilis should have been given in many more cases than it actually was, the percentage of cases in which syphilis was probably partly the cause of death ( 3.6 per cent.) was far below that in Runeberg's series (15.0 per cent.). This may to some degree be explained by the class to which the insured persons belonged being on the average different in the two series. In conclusion, I may further mention that, whereas in Runeberg's series $21 \cdot 3$ per cent. of the deaths could be assigned to tuberculous affections, in the present series $I$ find that in only 7.8 per cent. - that is to say, in 39 cases-are tuberculous affections mentioned as having been present, and in these 39 cases three of "fibroid phthisis" are included-viz., in men aged respectively 59, 61, and 63 years at death. In connexion with this relative rarity of tuberculosis it must be remembered that in 240 out of the 500 cases the age of 65 years or more was reached. Probably, therefore, the series of the English insurance company represents a higher average standard in regard to chances of longevity than did Professor Runeberg's series from the Kaleva Company.

Harley-street, W.

\section{Clinital Allotes:}

\section{MEDICAL, SURGICAL, OBSTETRICAL, AND THERAPEUTICAL.}

\section{FOREIGN BODIES IN THE CORNEA.}

BY WaTTER WILLIAMS, M.B.

THE extraction of small particles of iron or stone from the surface of the cornea is generally such an easy matter and, provided due precautions are taken, is attended with so little reaction that it might well appear presumptuous to relate a method which I have found on occasions to be serviceable.

When the little brown or black speck is situated, as is generally the case, towards the middle of the outer aspect the enlarged pupil which follows the instillation of cocaine makes it very difficult, and often impossible, to see the offending particle. To obviate this and to secure a clear view of the object to be removed I find it useful to instil a drop of eserine sulphate (1 per cent. solution), or preferably from 1 to 2 per cent. solution of pilocarpine hydrochloride, so as to neutralise the mydriatic effect of the cocaine. In this way one secures the anæsthetic effect of the cocaine without its drawbacks, for the eserine spreading the jris as a curtain behind the dark speck renders it visible and its removal comparatively easy, and that irrespectively of the direction in which the patient is looking.

There are doubtless many in active practice who may have found some such method as I mention to be of service, but its usefulness has so often forced itself on my attention, especially when scraping the so-called iron scale (the ferrosoferric oxide) which follows the deposition of iron in the corneal tissue that I thought a word about it might prove acceptable.

Portmadoc.

THE AURICULAR REFLEX.

By E. Donaldson, L.R.C.P. \& S. IREL.,

SURGEON TO THE LONDONDERRX EXE, EAR, AND THROAT HOSPITAL.

I AM much indebted to Dr. Walker Overend for his remarks on the above subject. ${ }^{1}$ When $I$ published my note I regret I did not know that he had already made observations on this reflex. After reading his last communication I sent for the patient whose case is recorded ${ }^{2}$ and whose reflex is easily obtained. I found that the middle-ear was quite dry, that the polypus was gone, and that the reaction was as lively as ever. A camel's-hair brush thrust into the neighbourhood of the external meatus produced a forward movement of the auricle effectively, quite as well, and I think better, than a puff of air. When testing with the air-bag it is well to use a nozzle with a small bore, for in this way a sudden forcible little blast can be produced. The use of the camel'shair bru-h, as suggested by Dr. Overend, is more convenient and better. When making observations care should be taken that the patient does not smile or close the eyes, as these movements are accompanied by upward movement of the auricle. It is probable that this reflex would have been long ago noticed but that aurists when inserting the speculum, insufflating powders, or applying anything to the meatus or middle-ear hold the auricle upwards and backwards to straighten the canal and by so doing often prevent this reflex movement.

Londonderry.

\section{d attlirur}

of

HOSPITAL PRACTICE, BRITISH AND FOREIGN.

Nulla autem est alia pro certo noscendi via, nisi quamplurimas et morborum et dissectionum historias, tum aliorum tum proprias collectas habere, et inter se comparare.-MoRgagni De Sed. et Caus. Morb., lib. iv., Proœmium.

\section{PRETORIA CIVIL HOSPITAL.}

A CASE OF LABOUR AT FULL TERM COMPLTCATED BY PLACENTA PR \&VIA AND HYDRAMNIOS; DELIVERY OF A

DEAD CHILD, FOLLOWED BY PUERPERAL FEVER;

TREATMENT BY ANTI-STREPTOCOCCIC SERUM ; RECOVERY COMPLICATED BY MALARIAI FEVER.

(Under the care of Dr. HERBERT JAMES GODWIN.)

THE value of anti-streptococcic serum in septicæmia is still far from being accurately determined and the question can only be decided by the careful report of cases in which the serum has been employed; we are glad, therefore, to be able to publish the following two cases, in which the im. provement that occurred appeared to be definitely due to the administration of anti-streptococcic serum. This remedial

1 The Lancet, Sept. 6th, 1902, p. 672. 2 THE LaNCET, August 23rd, 1902, p. 506 